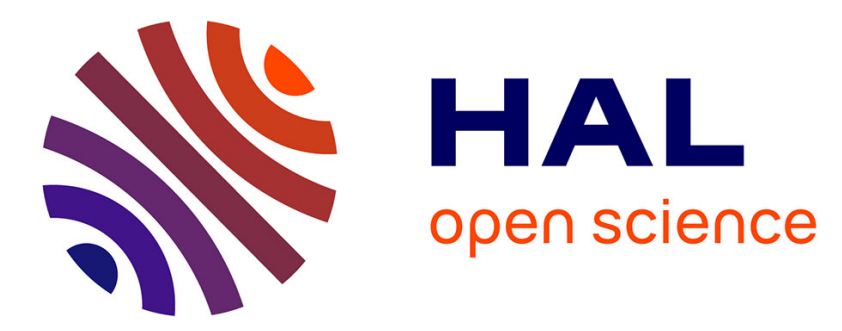

\title{
Randomly organized and self-assembled Na0.5Bi0.5TiO3 nanodots elaborated by sol-gel and pulsed laser deposition routes
}

\author{
Florian Jean, Jean-René Duclere, Fabien Remondiere, Alexandre Boulle, \\ Stéphanie Députier, Valérie Coudert, Maryline Guilloux-Viry
}

\section{To cite this version:}

Florian Jean, Jean-René Duclere, Fabien Remondiere, Alexandre Boulle, Stéphanie Députier, et al.. Randomly organized and self-assembled $\mathrm{Na} 0.5 \mathrm{Bi} 0.5 \mathrm{TiO} 3$ nanodots elaborated by sol-gel and pulsed laser deposition routes. Materials Letters, 2013, 107, pp.299-302. 10.1016/j.matlet.2013.06.021 . hal-00860835

\section{HAL Id: hal-00860835 https://hal.science/hal-00860835}

Submitted on 12 Sep 2013

HAL is a multi-disciplinary open access archive for the deposit and dissemination of scientific research documents, whether they are published or not. The documents may come from teaching and research institutions in France or abroad, or from public or private research centers.
L'archive ouverte pluridisciplinaire HAL, est destinée au dépôt et à la diffusion de documents scientifiques de niveau recherche, publiés ou non, émanant des établissements d'enseignement et de recherche français ou étrangers, des laboratoires publics ou privés. 


\title{
Randomly organized and self-assembled $\mathrm{Na}_{0.5} \mathrm{Bi}_{0.5} \mathrm{TiO}_{3}$ nanodots elaborated by sol-gel and pulsed laser deposition routes
}

\author{
F. Jean ${ }^{1}$, J.-R. Duclère ${ }^{1, *}$, F. Rémondière ${ }^{1}$, A. Boulle ${ }^{1}$, \\ S. Députier ${ }^{2}$, V. Coudert ${ }^{1}$, M. Guilloux-Viry ${ }^{2}$
}

${ }^{1}$ Laboratoire Science des Procédés Céramiques et de Traitements de Surface,

UMR 7315 CNRS-Université de Limoges, Centre Européen de la Céramique,

12, rue Atlantis, 87068 Limoges Cedex, France

\author{
${ }^{2}$ Institut des Sciences Chimiques de Rennes, UMR 6226 CNRS - Université de Rennes 1, \\ Equipe Chimie du Solide et Matériaux, 35042 Rennes Cedex, France
}

\begin{abstract}
This work reports for the first time on the elaboration, by both chemical (sol-gel) and physical (Pulsed Laser Deposition) routes, of lead-free ferroelectric $\mathrm{Na}_{0.5} \mathrm{Bi}_{0.5} \mathrm{TiO}_{3}$ nanodots deposited on bare $c$-sapphire single crystal substrates presenting a $5^{\circ}$ miscut angle along the [110] direction. Prior to any deposition, the sapphire substrates were treated at $1350^{\circ} \mathrm{C}$, during $24 \mathrm{~h}$ in air, in order to increase the height of the surface steps, reaching by this way $\sim 8 \mathrm{~nm}$. The experimental parameters adjusted for the growth of $\mathrm{Na}_{0.5} \mathrm{Bi}_{0.5} \mathrm{TiO}_{3}$ dots were the concentration of sols and the number of laser pulses (50 and 100) for the sol-gel and pulsed laser deposition routes, respectively. Whereas the sol-gel route leads to randomly organized $\mathrm{Na}_{0.5} \mathrm{Bi}_{0.5} \mathrm{TiO}_{3}$ nanodots in respect to the surface steps, the pulsed laser deposition route provokes the selfassembly for some important proportion of these dots along the same surface steps. Despite the lack of organization for the sol-gel dots, the latter present a much more regular distribution in size $(\sim 100$ and $\sim 10-20 \mathrm{~nm}$ as average lateral dimensions and height,
\end{abstract}


respectively) compared to dots deposited by laser ablation, where three different populations of grains can be observed. In each case, the dots do not seem to be epitaxially grown.

Keywords: nanodots, $\mathrm{Na}_{0.5} \mathrm{Bi}_{0.5} \mathrm{TiO}_{3}$, lead-free ferroelectric, sol-gel, pulsed laser deposition *Corresponding author: Jean-René Duclère

Email address: jean-rene.duclere@unilim.fr 


\section{Introduction}

Currently, lead-based compounds such as lead zirconate titanate $\mathrm{Pb}(\mathrm{Zr}, \mathrm{Ti}) \mathrm{O}_{3}(\mathrm{PZT})$ constitute the best family of piezoelectric and ferroelectric materials suitable for integration in devices, such as piezoelectric actuators, sensors and transducers [1,2]. However, due to health care and environmental problems, lead content must be reduced in such applications [3]. Since the last ten years, many efforts have been devoted in the field of lead-free materials [4]. Among the different lead-free materials available for substitution of the PZT's family, $\mathrm{Na}_{0.5} \mathrm{Bi}_{0.5} \mathrm{TiO}_{3}$ (NBT) [5] appears as a promising candidate on account of its good ferroelectric $\left(\mathrm{P}_{\mathrm{r}}=38\right.$ $\left.\mu \mathrm{C} / \mathrm{cm}^{2}, \mathrm{E}_{\mathrm{c}}=73 \mathrm{kV} / \mathrm{cm}\right)$ and piezoelectric properties $\left(\mathrm{d}_{33}=79 \mathrm{pC} / \mathrm{N}\right)[6]$.

In this letter, we first review the papers treating about pure NBT, doped-NBT and NBT-based nanocrystals, nanoparticles, etc... Globally, the reports can be sorted in various categories, which correspond to the various routes employed to achieve the synthesis of such nanomaterials. In brief, the first category corresponds to pure nano-NBT [7-16] and Fe- [17] or Mn-doped [18] nano-NBT produced from hydrothermal route. The second category of articles concerns pure NBT nanostructure [19] or fine particles with different shapes [20] elaborated by sol-gel route. Synthesis of NBT nanocrystalline powders is also reported from “derived" sol-gel processes: from polyvinyl alcohol route [21] and by stearic acid gel method [22]. "Hybrid" routes, like solution/sol-gel process [23], sol-gel/hydrothermal [24, 25] and self-assembly technique in combination with sol-gel method [26], were respectively used to produce NBT nanosized powders, nanowires, nanowhiskers and inverse opal photonic crystals. Other ways, like pyrogenation-with-sugar-protection and synthesis in molten salt, have been also applied for the fabrication of NBT nanopowders [27] or submicronic nanoparticles [28], respectively. In addition, high energy milling was used in order to obtain $\left(\mathrm{Bi}_{0.5} \mathrm{Na}_{0.5}\right)_{0.94} \mathrm{Ba}_{0.06} \mathrm{TiO}_{3}$ nanometric powders [29]. Finally, nanostructured $\mathrm{NBT}-\mathrm{BaTiO}_{3}$ 
whiskers were elaborated topochemically using $\mathrm{Na}_{2} \mathrm{Ti}_{6} \mathrm{O}_{13}$ as a host structure [30] and NBT nanocrystals were synthesized from either $\mathrm{Bi}_{2} \mathrm{Ti}_{4} \mathrm{O}_{11}$ [31] or $\mathrm{Bi}_{4} \mathrm{Ti}_{3} \mathrm{O}_{12}$ [32].

Recent literature dealing with lead-free ferroelectric nanocrystals and nanodots, like $\mathrm{BaTiO}_{3}$ [33, 34], $\mathrm{BiFeO}_{3}$ [35], as well as with lead-based $\left(\mathrm{PbTiO}_{3}\right)$ nanodots $[36,37]$, should finally be cited in order to testify to the high activity around this field of research and to the high quality of the published works.

However, up to this date, there is no report concerning the growth of NBT nanodots. Thus, elaborating and studying nanodots of such lead-free ferroelectric material is of importance, as the need for miniaturization of electrical devices is growing decades after decades. Therefore, this paper provides for the first time the experimental details regarding the elaboration of NBT nanodots deposited on miscut $c$-sapphire single crystal substrates by using both physical (Pulsed Laser Deposition (PLD)) and chemical (sol-gel - (SG)) routes. Serious attention is given to carefully prove that the deposited nanodots actually correspond to the NBT material.

\section{Experimental section}

The $c$-sapphire substrates used in this study were purchased with a $5^{\circ}$ miscut angle along the [110] direction. The samples were first placed into alumina crucibles to further avoid any contamination and then inserted into a muffle furnace and thermally treated in air at $1350^{\circ} \mathrm{C}$ during $24 \mathrm{~h}$, with heating and cooling ramps at $10 \% \mathrm{~min}$. These particular experimental conditions were selected based on earlier works in our laboratory [38]. Applying this thermal treatment allows increasing the height of the surface steps up to $\sim 8 \mathrm{~nm}$ by step-bunching [39], while the original height only corresponds to $c / 6=0.216 \mathrm{~nm}$ (with $c$ being the axis of the sapphire structure, described in the hexagonal system). As well, after such heating treatment, the average step width reaches approximately $130 \mathrm{~nm}$. Finally, prior to NBT 
deposition, the heat-treated sapphire substrates were systematically immersed in an ultrasonic bath and cleaned in acetone and isopropanol.

NBT nanodots were grown by sol-gel route. The sols were prepared as follows: stoichiometric ratio of bismuth acetate, anhydrous sodium acetate and titanium di-isopropoxyde bis-2,4 pentanedionate were added to an equimolar mixture of 1,3-propanediol, glacial acetic acid and deionized water [40]. Due to the hygroscopic feature of metallic acetate salts, bismuth and sodium acetates were stored and weighed in a glove box under inert $\left(\mathrm{N}_{2}\right)$ atmosphere. The reactants were slowly heated up to $105^{\circ} \mathrm{C}$ : after a reflux of 5 hours in air, the mother sol corresponded to a yellowish transparent solution. A distillation under reduced pressure allows concentrating the sols until $0.67 \mathrm{~mol} . \mathrm{L}^{-1}$ and to distill off by-products. Using a commercial spin coater, diluted NBT sols with different concentrations were then spun at $3000 \mathrm{rpm}$ for 30 seconds on the aforementioned $c$-sapphire substrates. The as-deposited samples were dried at $360^{\circ} \mathrm{C}$ on a hot plate for 5 minutes and then pyrolysed at $700^{\circ} \mathrm{C}$ for 5 minutes in a preheated furnace.

NBT nanodots were also grown by PLD from a home-made sintered Na-enriched target, at a temperature of $\sim 600^{\circ} \mathrm{C}$ and under an oxygen pressure of 0.2 mbar [41]. Laser ablation was performed using a $\mathrm{KrF}$ excimer laser $(\lambda=248 \mathrm{~nm}$, pulse duration $=20 \mathrm{~ns})$ operated at $5 \mathrm{~Hz}$,

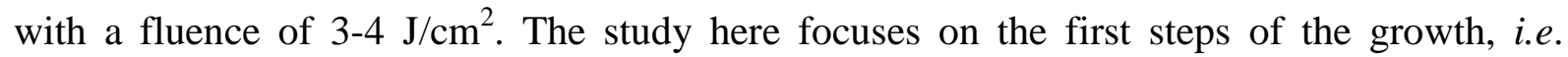
samples grown with a limited number of laser pulses in order to avoid the coalescence of isolated islands.

The structure of NBT nanodots was characterized using X-ray diffraction (XRD) in both classical $\theta-2 \theta$ and grazing incidence geometries. In the latter geometry, the incident $\theta$ angle was fixed at $2^{\circ}$. In each configuration, due to the very limited amount of deposited material, XRD patterns were recorded using a long acquisition time per step (approximately 22 and $14 \mathrm{~s}$, respectively) to allow collecting data of sufficiently good quality. 
The surface of the samples was observed by Atomic Force Microscopy (AFM).

\section{Results and discussion}

\subsection{Elaboration of NBT nanodots by the sol-gel route}

In order to get isolated NBT islands, the concentration of the sols was adapted (dilution from the mother solution). Three concentrations were tested: namely $0.2,0.05$ and $0.02 \mathrm{~mol} . \mathrm{L}^{-1}$. The first concentration conducts to a continuous film with a thickness estimated in the 10-20 $\mathrm{nm}$ range, based on ellipsometry data (not shown here) and depending on the model employed to fit the corresponding data. The last solution is too diluted, leading to a very reduced amount of material present at the surface: thus, the probability of finding nano-objects via AFM observations is almost close to zero. In the end, the intermediate concentration constitutes a good compromise in order to obtain isolated NBT nanoislands present in sufficient large quantity.

The aspect of the surface is revealed in Figure 1. The dots are homogeneously distributed, with a rather regular distribution in sizes and lateral dimensions around 100-150 $\mathrm{nm}$ and height $\sim 15 \mathrm{~nm}$, as could be evidenced from the section profile in the insert of Figure 1 . They seem to be randomly organized, as they are positioned along the surface steps or at the edge of the steps. The steps are still clearly visible, suggesting the incomplete coverage of the sapphire surface. Finally, the dots appear to be rather spherical and do not display any other particular shapes.

Figure 2 corresponds to the XRD data acquired in grazing incidence geometry, for the sample prepared from the sol having a concentration of 0.2 mol.L ${ }^{-1}$. Such XRD pattern serves as a reference in order to demonstrate that the deposited material actually corresponds to NBT. Indeed, attempts to directly characterize the sample elaborated from the sol having a concentration of $0.05 \mathrm{~mol} . \mathrm{L}^{-1}$ (i.e. the sample displayed in Fig. 1) were unfortunately 
unsuccessful, due to the reduced amount of NBT material. However, for the latter sample, we strongly believe that there is no particular reason for the structure to be modified.

Furthermore, NBT nanodots are not epitaxially grown on single crystal sapphire substrates, despite a plausible texturation (the intensity of the (211) Bragg reflection is abnormally high) that remains to be explained.

\subsection{Elaboration of NBT nanodots by the PLD route}

In order to elaborate NBT nanodots by PLD, the idea applied here is extremely simple: the laser is operated with reduced amounts of pulses (here, typically 50 and 100) in order to obtain isolated nano-islands and avoid their coalescence. Extra samples, corresponding to larger amounts of laser pulses (200 and 500), were grown to serve as XRD reference data.

Figure 3 represents the observation of the surface for the sample made from 100 laser shots at the target. The microstructure of the sample elaborated from 50 laser pulses appears very similar. Above 100 laser pulses (i.e. 200 and 500), the islands start to coalesce.

The aspect of the PLD samples is somehow "opposite" to that of the SG ones. Indeed, the distribution in size is now much more irregular. Three different populations of nanodots can be distinguished (see the insert of Figure 3):

- the first one corresponds to larger dots with lateral dimensions up to $150 \mathrm{~nm}$ and height above $20 \mathrm{~nm}$

- the second population is constituted by smaller dots with lateral dimensions and height below 50 and $5 \mathrm{~nm}$, respectively

- in the third category, the dots have lateral dimensions between 50 and $100 \mathrm{~nm}$, combined with heights ranging from 10 to $15 \mathrm{~nm}$ 
The proportions of the various populations of nanodots are very different. Whereas the percentage of the first population is rather reduced, both the second and third populations constitute the big majority of the dots and seem to be present in similar proportions.

Furthermore, a good proportion of the nanodots is now clearly positioned along the surface steps. Therefore, contrary to the SG route, our observations indicate that the self-assembly of NBT nanodots can be reached via the PLD route, to some rather good extent, provided one uses appropriate templates. In addition, as observed in the case of SG samples, the nanodots grown by PLD also display a rather spherical shape.

Finally, in the case of PLD samples grown for 200 and 500 laser shots, the XRD data provided in Figure 4 unambiguously prove that the elaborated material correspond to NBT. Below 200 laser pulses, in our experimental configuration, it is impossible to detect any Bragg peaks. However, as previously discussed, we see no specific reason why the NBT structure should be modified for a reduced number of laser shots (i.e. 50 or 100). The last information that can be extracted from the XRD patterns is that, in opposite to the SG sample where a plausible texturation was suggested, all the PLD samples appear to be completely polycrystalline.

We will end up this letter by briefly mentioning that one last issue remains to be addressed: whatever the employed route, there still exists some ambiguity regarding the determination of the actual structure of the deposited NBT material. Indeed, NBT can crystallize adopting three different polymorphs: namely rhombohedral, tetragonal or cubic, depending on the temperature. The rhombohedral variety, which corresponds to the R3c polar structure, is the one expected to be stable at room temperature. Unfortunately, using only XRD and due to the weak diffracted intensities as well as the reduced number of detected Bragg peaks, it becomes impossible, so far, to strictly prove that NBT nanodots crystallize in the R3c space group. 


\section{Conclusion}

This letter provides for the first time the experimental evidence for the elaboration of polycrystalline $\mathrm{Na}_{0.5} \mathrm{Bi}_{0.5} \mathrm{TiO}_{3}$ nanodots by both sol-gel and pulsed laser deposition methods. Atomic Force Microscopy observations reveal that the nano-islands can be isolated for sufficiently diluted sol concentrations (sol-gel route) or for sufficiently reduced amounts of laser pulses (pulsed laser deposition route). Each route will then present its own advantages/drawbacks: in the case of the sol-gel route, the nanodots are randomly distributed in respect to the sapphire surface steps but present a more homogeneous distribution in size. At the opposite, for the pulsed laser deposition route, a good proportion of the nanodots is located along the surface steps, thus proving the possibility for self-assembling, but the dots present more irregular lateral dimensions and height. Finally, for both routes, X-ray diffraction data testify to the correct deposition of $\mathrm{Na}_{0.5} \mathrm{Bi}_{0.5} \mathrm{TiO}_{3}$ material. However, as briefly discussed above, our main issue remains to strictly prove that the crystal structure of $\mathrm{Na}_{0.5} \mathrm{Bi}_{0.5} \mathrm{TiO}_{3}$ is actually the $\mathrm{R} 3 \mathrm{c}$ polar structure: Transmission Electron Microscopy experiments are currently carried out to shed some light on this open question. 


\section{References}

[1] B. Jaffe, W. R. Cook, and H. Jaffe, Piezoelectric Ceramics (Academic, New York, 1971).

[2] F. Levassort, P. Tran-Huu-Hue, E. Ringaard, and M. Lethiecq, J. Eur. Ceram. Soc. 21, $1361(2001)$.

[3] EU-Directive 2002/95/EC: Restriction of the Use of Certain Hazardous Substances in Electrical and Electronic Equipment (RoHS), Off. J. Eur. Union, 46, [L37] 19-23 (2003).

[4] J. Rödel, W. Jo, K. T. P. Seifert, E.-M. Anton, T. Granzow, and D. Damjanovic, J. Am. Ceram. Soc. 92, 1153 (2009).

[5] G. A. Smolenski, V. A. Isupov, A. I. Agranovskaya, and N. N. Krainik, Sov. Phys. Solid State 2, $2651(1961)$

[6] Y. Hiruma, H. Nagata and T. Takenaka, J. Appl. Phys. 105, 084112 (2009).

[7] L. Wang, W. Wang, Int. J. Hydrogen Energ., 37 (2012) 3041.

[8] J. Li, G. Wang, H. Wang, C. Tang, Y. Wang, C. Liang, W. Cai, L. Zhang, J. Mater. Chem., 19 (2009) 2253.

[9] K. Kanie, Y. Numamoto, S. Tsukamoto, T. Sasaki, M. Nakaya, J. Tani, H. Takahashi, A. Muramatsu, Mater. Trans., 52 (2011) 1396.

[10] L. Yang, Yonggang. Wang, Yujiang Wang, Adv. Mater. Res., 463-464 (2012) 777.

[11] X. Zhang, W. Tang, H. Wu, B. Zhang, X. Zheng, Adv. Mater. Res., 482-484 (2012) 2573.

[12] M. M. Lencka, M. Oledzka, R. E. Riman, Chem. Mater., 12 (2000) 1323.

[13] T. Lu, J. Dai, J. Tian, W. Song, X. Liu, L. Lai, H. Chu, X. Huang, X. Liu, J. Alloy. Compd., 490 (2010) 232.

[14] Y. Wang, G. Xu, L. Yang, Z. Ren, X. Wei, W. Weng, P. Du, G. Shen, G. Han, Ceram. Int., 35 (2009) 1657.

[15] K. Sardar, R. I. Walton, J. Solid State Chem., 189 (2012) 32. 
[16] T. Setinc, M. Spreitzer, M. Logar, D. Suvorov, J. Am. Ceram. Soc., 94 (2011) 3793.

[17] Y. Wang, G. Xu, L. Yang, Z. Ren, X. Wei, W. Weng, P. Du, G. Shen, G. Han, Mater. Sci. Poland, 27 (2009) 471.

[18] Yonggang. Wang, Yujiang Wang, Adv. Mater. Res., 311 (2011) 2110.

[19] M. Hafizuddin Haji Jumali, S. Mariam Mohamad, R. Awang, M. Yahaya, M. Mat Salleh, Adv. Mater. Res., 364 (2012) 412.

[20] K. Kanie, H. Sakai, J. Tani, H. Takahashi, A. Muramatsu, Mater. Trans., 48 (2007) 2174.

[21] L. Haitao, W. Xiaohui, L. Longtu, J. Phys: Conf. Series, 188 (2009) 012058.

[22] J. Hao, X. Wang, R. Chen, L. Li, Mater. Chem. Phys., 90 (2005) 282.

[23] C. Y. Kim, T. Sekino, K. Niihara, J. Am. Ceram. Soc., 86 (2003) 464.

[24] Y.-D. Hou, L. Hou, J.-L. Zhao, M.-K. Zhu, H. Yan, J. Electroceram., 26 (2011) 37.

[25] J.-B. Liu, H. Wang, Y.-D. Hou, M.-K. Zhu, H. Yan, M. Yoshimura, Nanotechnology, 15 (2004) 777.

[26] Z. Yang, J. Zhou, X. Huang, Q. Xie, M. Fu, B. Li, L. Li, J. Alloy. Compd., 471 (2009) 241.

[27] L. Sun, J. Q. Qi, P. Du, X. H. Wang, L. T. Li, Mater. Chem. Phys., 113 (2009) 329.

[28] P. Setasuwon, S. Kijamnajsuk, Adv. Mater. Res., 55-57 (2008) 161.

[29] M.-S. Yoon, N. H. Khansur, B.-K. Choi, Y.-G. Lee, S.-C. Ur, Ceram. Int., 35 (2009) 3027.

[30] D. Maurya, V. Petkov, A. Kumar, S. Priya, 41 (2012) 5643.

[31] P. Setasuwon, N. Vaneesorn, S. Kijamnajsuk, A. Thanaboonsombut, Sci. Techn. Adv. Mater., 6 (2005) 278.

[32] J. Qi, L. Sun, P. Du, L. Li, J. Am. Ceram. Soc., 93 (2010) 1044.

[33] M. J. Polking, M.-G. Han, A. Yourdkhani, V. Petkov, C. F. Kisielowski, V. V. Volkov, Y. Zhu, G. Caruntu, A. P. Alivisatos, R. Ramesh, Nature Materials, 11 (2012) 700.

[34] L. J. McGilly, J. M. Gregg, Appl. Phys. Lett., 98 (2011) 132902. 
[35] I. Jung, J. Y. Son, J. Am. Ceram. Soc., 95 (2012) 3716.

[36] J. Li, M. Luo, W. Weng, K. Cheng, P. Du, G. Shen, G. Han, Appl. Surf. Sci., 256 (2009) 342.

[37] J. Kim, J. Hong, M. Park, W. Zhe, D. Kim, Y. J. Jang, D. H. Kim, K. No, Adv. Funct. Mater., 21 (2011) 4277.

[38] E. Thune, A. Boulle, D. Babonneau, F. Pailloux, W. Hamd, R. Guinebretière, Appl. Surf. Sci., 256 (2009) 924.

[39] R. Bachelet, S. Cottrino, G. Nahélou, V. Coudert, A. Boulle, B. Soulestin, F. Rossignol, R. Guinebretière, A. Dauger, Nanotechnology, 18 (2007) 015301.

[40] D. Alonso-Sanjose, R. Jimenez, I. Bretos, M. L. Calzada, J. Am. Ceram. Soc., 92 (2009) 2218.

[41] M. Bousquet et al., J. Appl. Phys. 107 (2010) 034102. 


\section{Figure captions}

Figure 1: AFM observation of the surface of the sample elaborated from the sol having a concentration of $0.05 \mathrm{~mol} \cdot \mathrm{L}^{-1}$. The insert displays a typical section profile measured for NBT SG nanodots.

Figure 2: XRD data acquired in grazing incidence geometry for the sample elaborated from the sol presenting a concentration of $0.2 \mathrm{~mol} . \mathrm{L}^{-1}$.

Figure 3: AFM observation of the surface of the sample elaborated from 100 laser pulses. Two different section profiles are indicated in order to highlight the diversity in height and lateral dimensions of the NBT PLD nanodots.

Figure 4: XRD $\theta-2 \theta$ data collected for the PLD samples elaborated from: (a) 200 laser pulses, (b) 500 laser pulses. In the latter case, the intensity has been intentionally shifted for more clarity. 


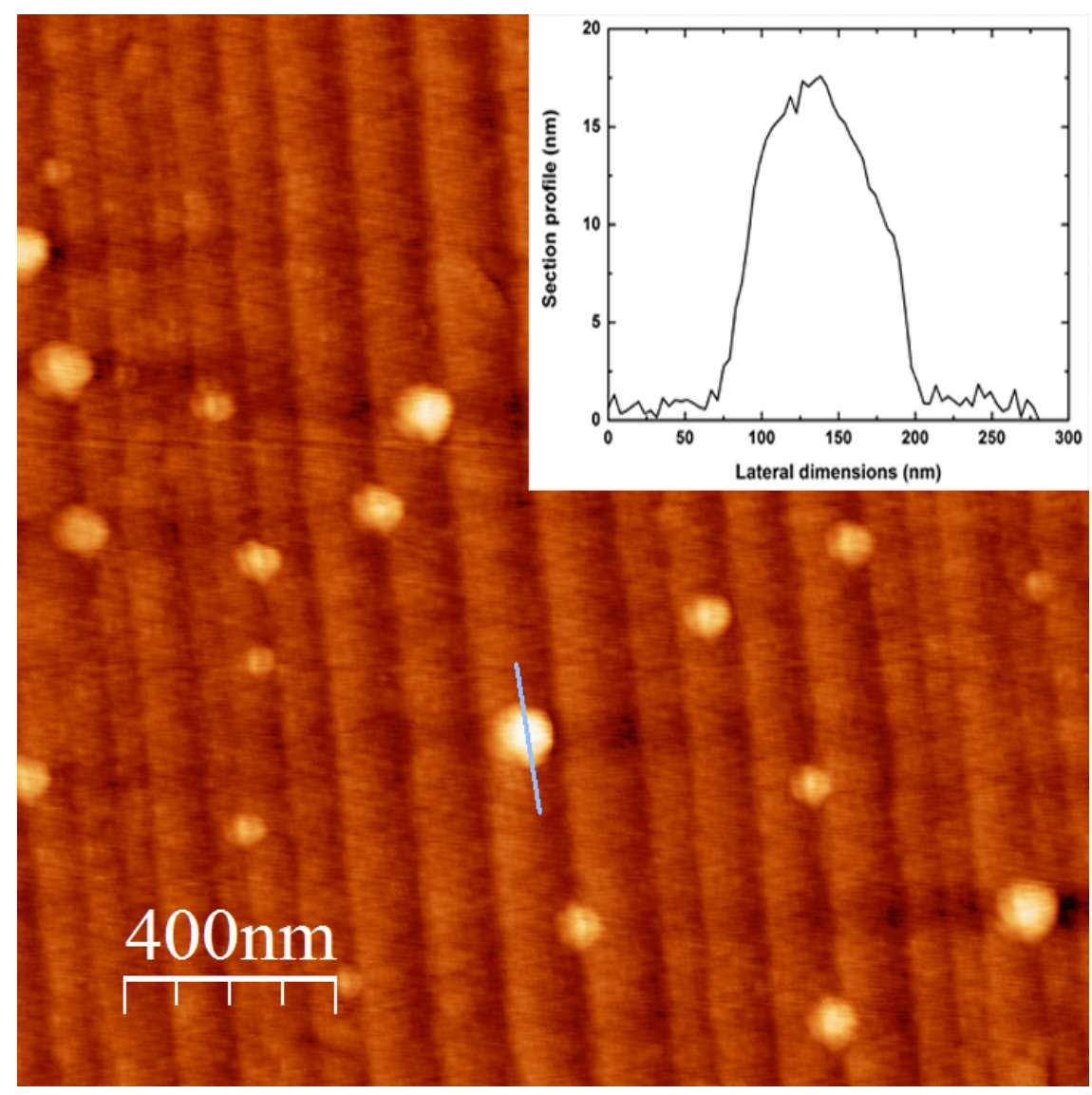

Figure 1 


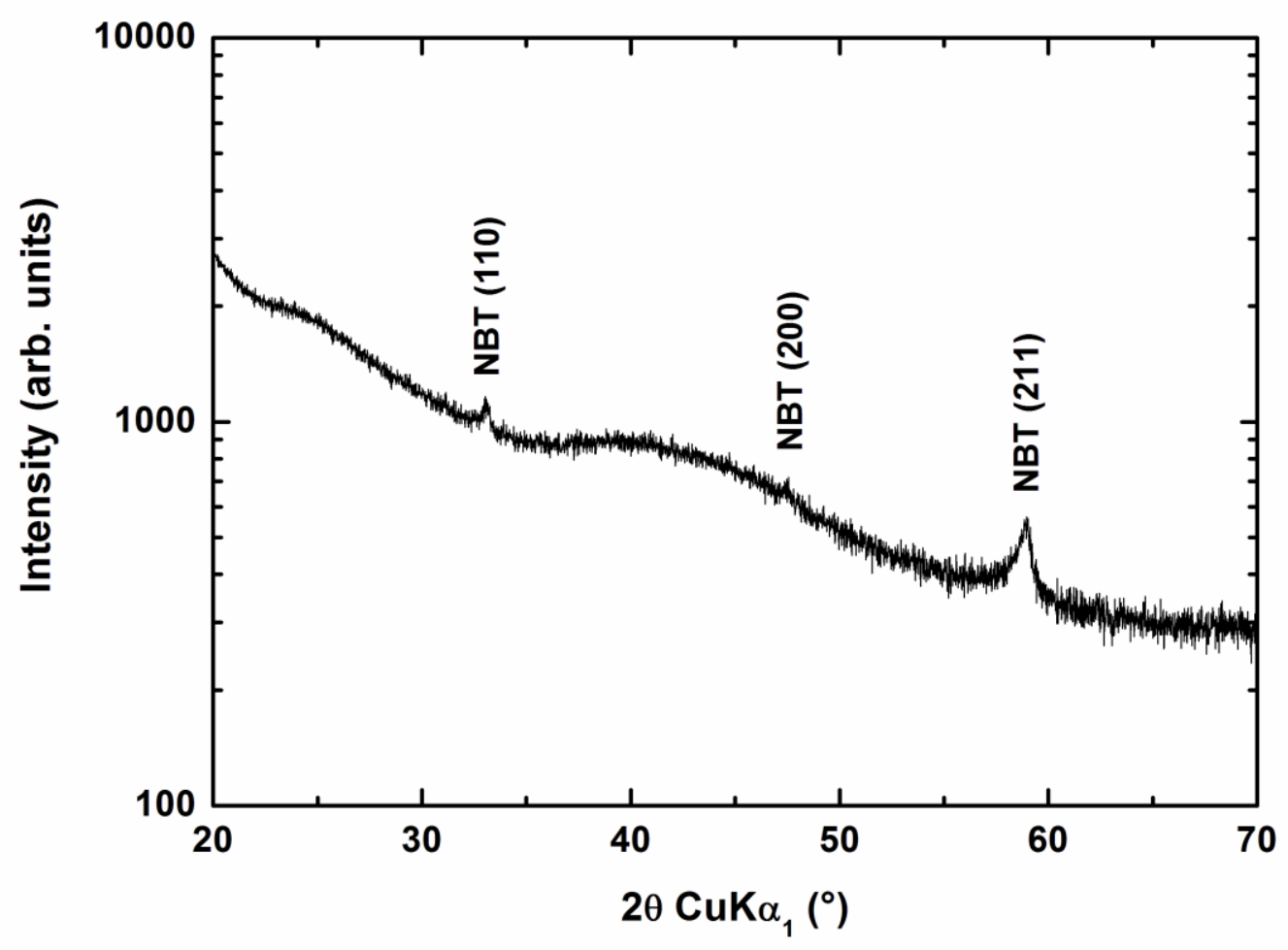

Figure 2 

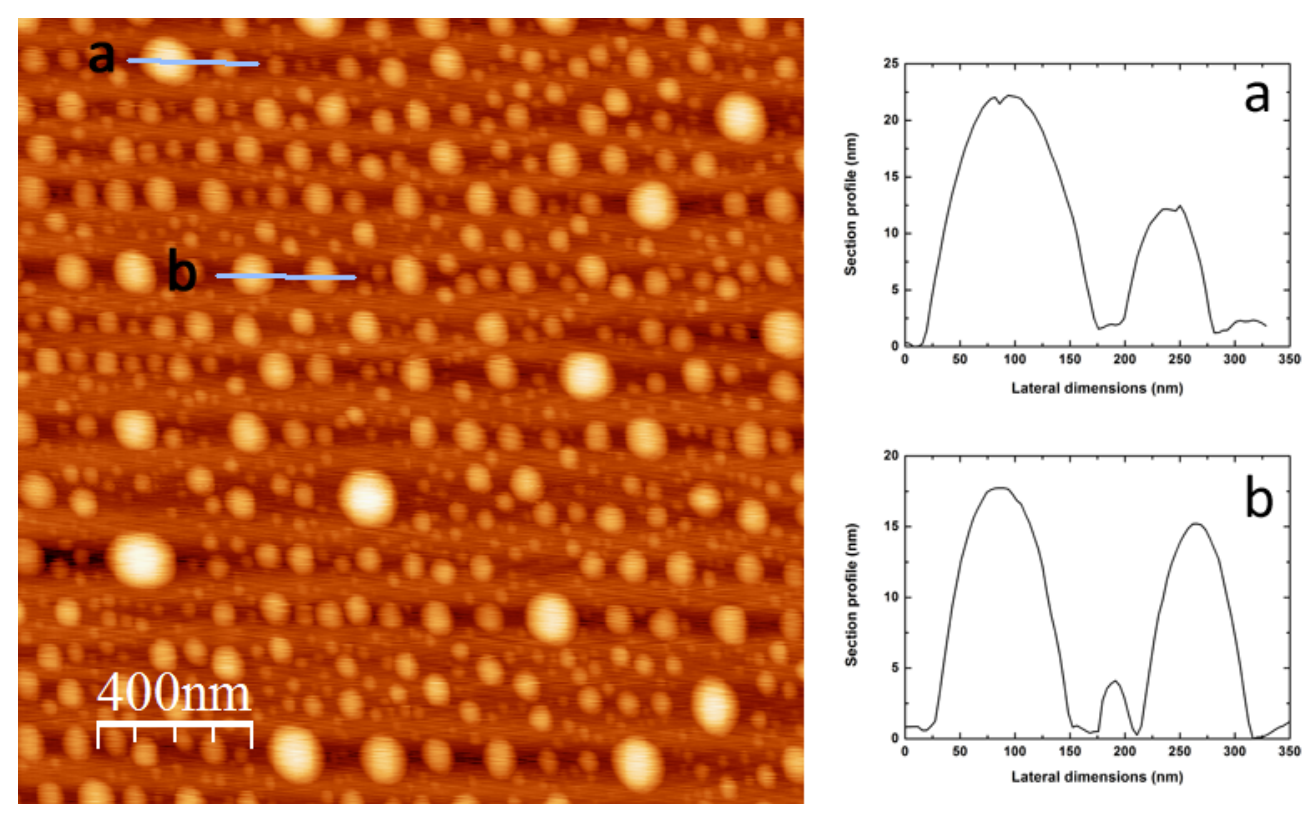

Figure 3 


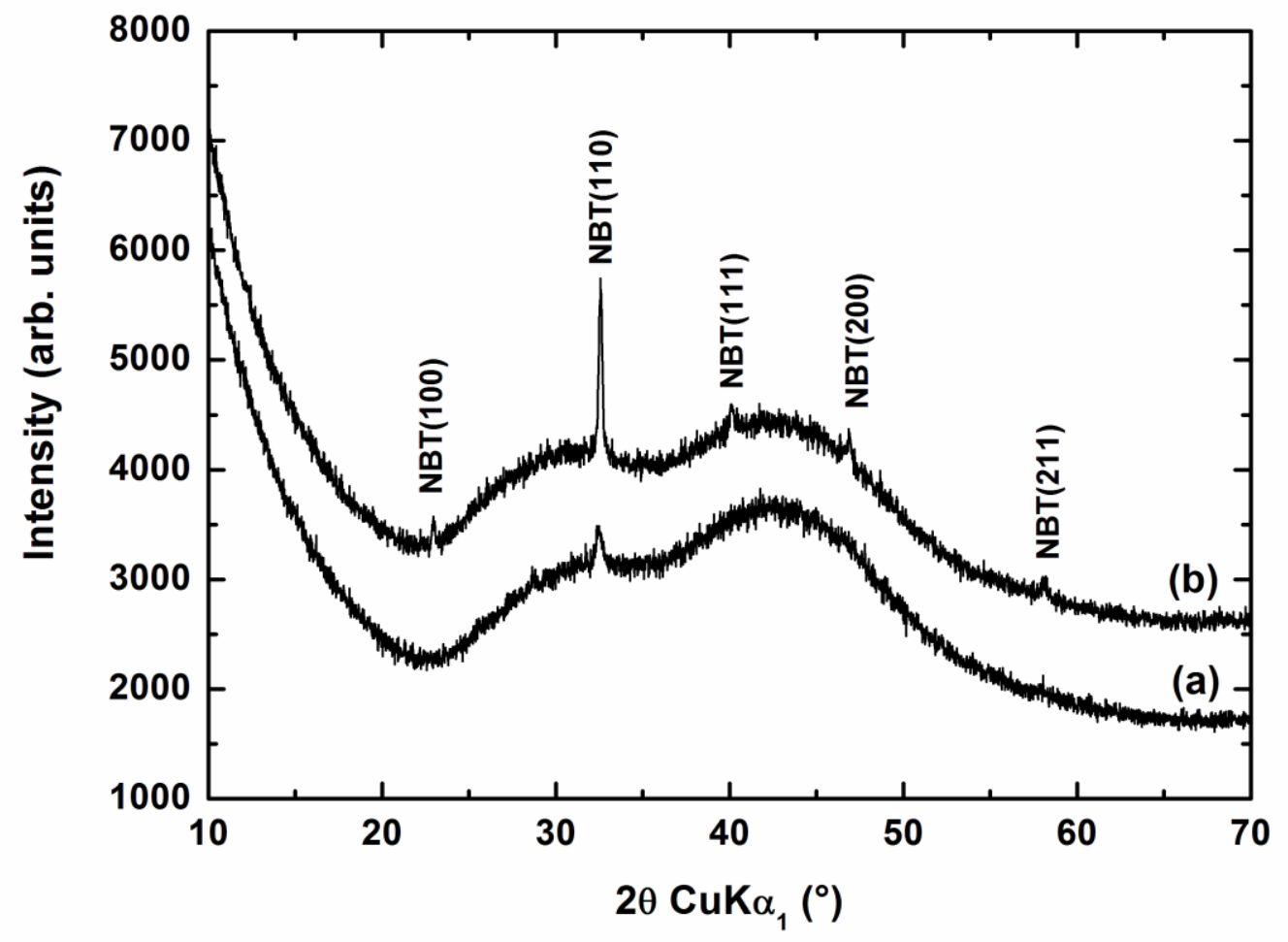

Figure 4 